\title{
Exemplo de aplicação do método de Pesquisa-ação para a solução de um problema de sistema de informação em uma empresa produtora de cana-de-açúcar
}

\author{
Example of an application of the Action Research method \\ for the solution of an information system problem in \\ a sugarcane producing company
}

\author{
Eugênio Pacceli Costa \\ Paulo Rogério Politano \\ Néocles Alves Pereira ${ }^{1}$
}

\begin{abstract}
Resumo: As empresas agrícolas produtoras de cana-de-açúcar lidam normalmente com muitos problemas operacionais, devido, acima de tudo, ao caráter sazonal de sua produção. Por outro lado, enfrentam também muitas dificuldades administrativas, principalmente no que se refere à utilização e controle de mão de obra. Necessitam de ampla faixa de competências, que vai do mais simples serviço manual à utilização de serviços técnicos especializados. Isso, associado ao caráter permanente da cultura de cana-de-açúcar, gera enormes complicações na contabilização de seus custos. A proposta deste trabalho consiste em utilizar a metodologia de Pesquisa-ação, juntamente com métodos e técnicas de Modelagem de Processos de Negócios para identificar direcionadores de custos de mão de obra e apoiar o desenvolvimento de um sistema para automatizar a distribuição e alocação desses custos na contabilidade. Utilizou-se do método de Pesquisa-ação baseado no roteiro McKay e Marshall, que demonstrou ser eficiente e eficaz no diagnóstico de problema organizacional e na sua solução.
\end{abstract}

Palavras-chave: Pesquisa-ação. Modelagem de processos de negócios. Direcionadores de custo. Agronegócio.

\begin{abstract}
Sugarcane industries usually deal with several operation problems mainly due to seasonality. On the other hand, they also face many administrative difficulties; particularly when it comes to issues related to and manpower employment and control which require a broad range of skills and abilities, from a simple manual labor to jobs skilled trade jobs. These factors associated to the fact that sugarcane is a permanent crop can lead to cost accounting problems. The purpose of this study is to use the action research methodology as well as the methods and techniques of Business Processes Modeling to identify manpower cost drivers and to support the development of a distribution and allocation automation system for cost accounting. The method of action research used was based on that proposed by McKay and Marshall, which proved efficient and effective in diagnosing organizational problems and providing solutions.
\end{abstract}

Keywords: Action research. Business processes modeling. Cost drivers. Agri-business.

\section{Introdução}

A administração de empresas em um cenário de mudanças constantes é uma tarefa cada vez mais complexa. Com isso, estudos relacionados a assuntos do ambiente organizacional devem ser conduzidos de forma sistêmica. Holanda e Riccio (2010) afirmam que os problemas organizacionais precisam ser pesquisados de forma coerente com sua natureza e sugerem que diferentes abordagens suscitam diferentes estratégias metodológicas. Thiollent (1997) propõe um enfoque metodológico por meio da Pesquisaação nas organizações, sejam elas com ou sem fins lucrativos, para auxiliar os processos de estudo e análise de problemas com a gestão. Isso porque, o maior objetivo da Pesquisa-ação é proporcionar novas informações, gerar e produzir conhecimento que traga melhorias e soluções para toda a organização (CAZZOLATO, 2008).

Thiollent (1997) afirma que em pesquisa organizacional, técnicas de diagnóstico, aplicação de questionários, entrevistas e estudos de caso são os métodos ou técnicas de maior divulgação. Todavia, desde a década de 1940, a pesquisa-ação é apresentada

\footnotetext{
'Departamento de Engenharia de Produção, Universidade Federal de São Carlos - UFSCar, CEP 13565-905, São Carlos, SP,

Brasil, e-mail: eugenio@sisger.com.br; paulo@dc.ufscar.br; neocles@ufscar.br
}

Recebido em 4/8/2011 — Aceito em 18/9/2013

Suporte financeiro: Nenhum. 
como um método apropriado para conhecer e intervir nas organizações.

Com relação ao desenvolvimento de sistemas de informação, Cunha e Figueiredo (2002) afirmam que o aumento da influência sócio-organizacional nesse assunto implica sérios desafios para a aplicação da maioria das abordagens tradicionais de pesquisa, isso porque o rigor destes métodos se torna cada vez mais irreal nesses contextos. Uma pesquisa nessas condições, com a necessidade adicional de assumir uma postura ágil e flexível, e com a obrigação de garantir que o conhecimento adquirido na prática promova o desenvolvimento de uma teoria, gera um novo conjunto de dificuldades. Nesse contexto, Thiollent (2005) afirma que a pesquisa-ação serve para identificar problemas e desenvolver um programa de ação a ser acompanhado e avaliado. Dessa forma, a pesquisa-ação é um modo de intervenção dos analistas de sistemas nas organizações e, em geral, limita-se à esfera dos dirigentes e usuários da informação.

Este trabalho apresenta um exemplo do uso do método de Pesquisa-ação para a solução de um problema real com contabilização de custos de mão de obra do sistema de informação de uma empresa produtora de cana-de-açúcar. Ilustra como a abordagem acadêmica mostrou-se totalmente adequada à solução do problema estudado. O caráter interativo do método, com o envolvimento do pesquisador com as ações implementadas, sempre amparadas com a revisão da literatura, teve grande importância para a convergência para os resultados esperados.

\section{Referencial teórico}

Este tópico apresenta uma breve revisão da literatura sobre o método de Pesquisa-ação e sobre a abordagem utilizada para o desenvolvimento deste trabalho.

\subsection{Pesquisa-ação}

A pesquisa-ação consiste essencialmente em acoplar pesquisa e ação em um único processo, no qual os atores implicados participam, junto com os pesquisadores, para chegarem interativamente a elucidar a realidade em que estão inseridos, identificando problemas coletivos, buscando e experimentando soluções em situação real. Simultaneamente, há produção e uso de conhecimento (THIOLLENT, 1997).

Para McKay e Marshall (2001), a essência da Pesquisa-ação está encapsulada em seu nome: representa uma justaposição de pesquisa e ação, em outras palavras, de prática e teoria. Assim como uma abordagem de pesquisa comprometida com a produção de conhecimento por meio da busca de soluções de problemas ou melhorias em situações práticas da "vida-real".

Segundo Coughlan e Coghlan (2002), pesquisadores em projetos de pesquisa-ação não são meros observadores de algo que está acontecendo, mas trabalham e fazem acontecer e que existem dois objetivos: resolver um problema e contribuir com a ciência. A pesquisa-ação é interativa, requer a cooperação entre o pesquisador e profissionais. Lida com constante ajuste entre novas informações, novos eventos e trata fundamentalmente de mudanças, objetivando um entendimento holístico de um projeto de reconhecida complexidade.

Para Thiollent (1997), a pesquisa deve ser conduzida de modo que não seja predeterminada pelos interesses dominantes que atravessam a organização. De acordo com a ética profissional, há um constante compromisso com a verdade e com a compreensão compartilhada entre os atores que se relacionam na situação investigada. Neste contexto de pesquisa organizacional, o projeto de pesquisa-ação agrega técnicas de pesquisa a serem aplicadas nas organizações.

Thiollent (1997) apresenta um conjunto de condições de compromisso participativo necessárias para tornar o projeto de pesquisa-ação sustentável, que são listadas a seguir.

- A iniciativa de pesquisa parte de uma demanda de pessoas ou grupos de pessoas que ocupam as posições de topo do poder;

- Os objetivos são definidos com autonomia dos atores e com mínima interferência de membros da estrutura formal;

- Todos os grupos sociais implicados no problema escolhido como assunto da pesquisa são chamados para participar do projeto e de sua execução;

- Todos os grupos têm liberdade de expressão. Medidas são tomadas para evitar censuras ou represálias;

- Todos os grupos são informados no desenrolar da pesquisa;

- As possíveis ações decorrentes da pesquisa são negociadas entre os proponentes e os membros da estrutura formal;

- Em geral, as equipes internas que promovem a pesquisa são auxiliadas por consultores ou pesquisadores externos.

O planejamento de uma pesquisa-ação é muito flexível, contrariamente a outros tipos de pesquisa, não segue uma série de fases rigidamente ordenadas. Há sempre um vaivém entre várias preocupações a serem adaptadas em função das circunstâncias e da dinâmica interna do grupo e dos pesquisadores no seu relacionamento com a situação investigada. Mas, de qualquer forma, a técnica principal, em torno da qual as outras gravitam, é a do "seminário", pois consiste em examinar, discutir e tomar decisões acerca do processo de investigação. 
Para McKay e Marshall (2001), o pesquisador deve, em colaboração como membro de uma organização, se envolver na mudança de uma situação problemática e com isso gerar conhecimento com os resultados obtidos.

No contexto organizacional, a pesquisa-ação é concebida com uma estrutura de interação clientes/ pesquisadores ou consultores com procedimento em cinco fases, bastante clássico nas áreas de tecnologia e organização (THIOLLENT, 1997):

- Diagnóstico para identificar um problema na organização

- Planejamento da ação, considerando as ações alternativas para resolver o problema

- Execução das ações, com seleção de um roteiro de ação

- Avaliação das consequências da ação

- Aprendizagem específica e identificação dos ensinamentos da experiência com retorno ao

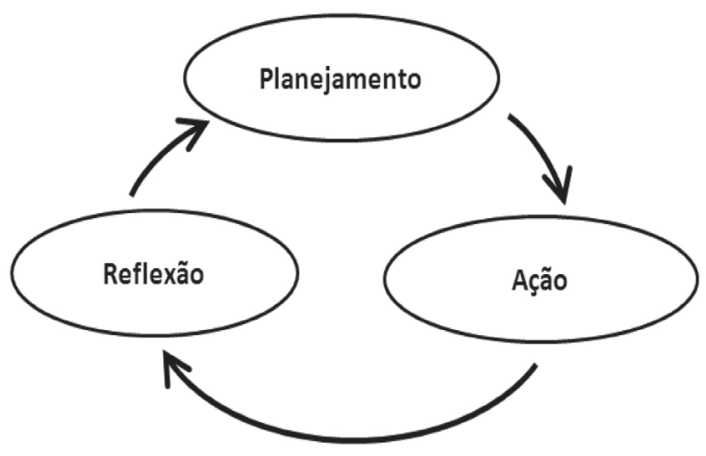

Figura 1. Ciclo simplificado da Pesquisa-ação. Fonte: Dick (2000). ponto de partida para evidenciar o generalizável adquirido sobre o problema.

Dick (2000) afirma que a caracterização da pesquisa-ação varia de um autor para outro, no entanto existe um conjunto de pontos comuns a todos:

- Atuar em uma situação existente com duplo objetivo e aperfeiçoar e ampliar o conhecimento sobre o assunto.

- Possuir uma natureza cíclica: executar uma série de etapas repetidamente. O ciclo varia de acordo com o autor, mas, pelo menos, deve incluir as etapas na Figura 1.

- Possuir uma natureza reflexiva: uma reflexão crítica sobre o próprio processo de pesquisa, bem como dos resultados obtidos é uma parte importante do ciclo.

- É predominantemente qualitativa, embora quantificações sejam possíveis em algumas situações.

McKay e Marshall (2001) apresentam um esquema para o desenvolvimento de um projeto de pesquisa-ação constituído por oito etapas, como pode ser visto na Figura 2.

As etapas ilustradas na Figura 2 são descritas como segue: a Etapa 1, Identificação do Problema, consiste na tarefa do pesquisador em identificar o problema que tenha interesse em resolver ou perguntas que possam ser respondidas com a pesquisa. Na Etapa 2, o pesquisador deve se empenhar em promover uma ampla revisão de literatura em busca de teorias que possam estar alinhadas com fatos relevantes sobre o problema e sirvam para dar suporte à solução do problema identificado na Etapa 1. A Etapa 3,

1

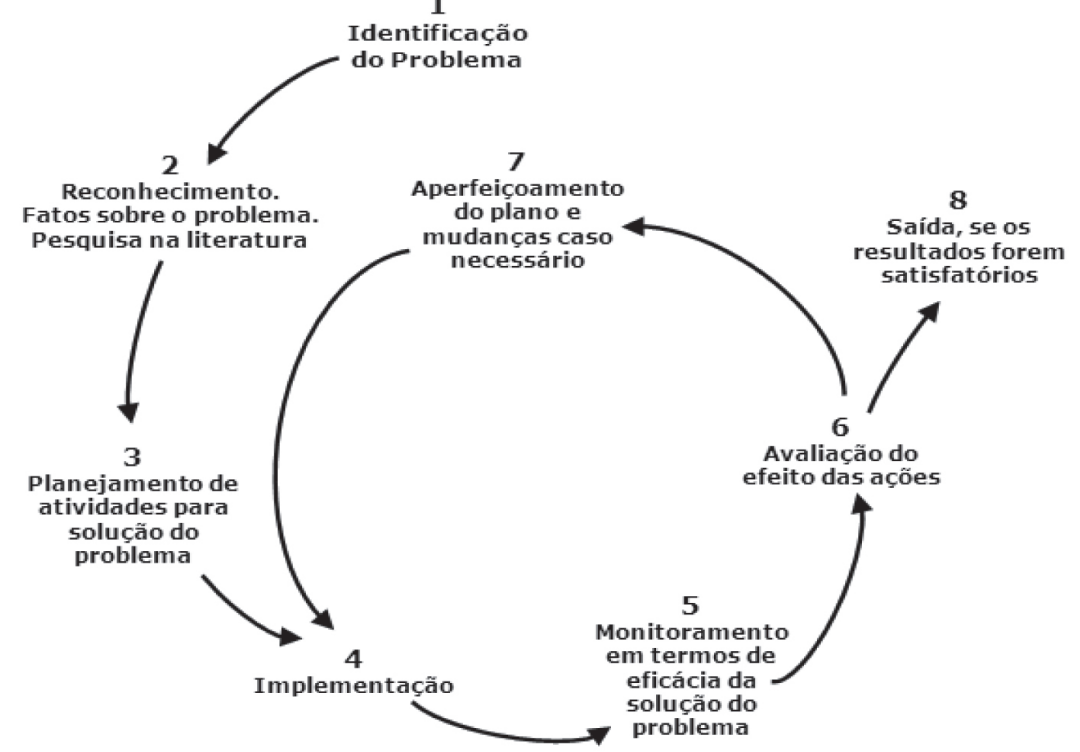

Figura 2. Os passos de um projeto de Pesquisa-ação. Fonte: Adaptado de McKay e Marshall (2001). 
consiste em desenvolver um plano de ações para a solução do problema. Na Etapa 4, o plano de ação desenvolvido na etapa anterior deve ser colocado em prática. A Etapa 5 consiste em monitorar as ações implementadas para saber se os resultados encontrados estão de acordo com o que se esperava para a solução do problema. A Etapa 6 serve para a avaliação do efeito das ações. Esse é um ponto de decisão. Caso as ações implementadas na Etapa 4 tenham sucesso total e o problema tenha sido resolvido, é possível passar diretamente para a Etapa 8. Caso contrário ações corretivas deverão ser implementadas na Etapa 7. A Etapa 7 deverá ser implementada caso o plano de ações elaborado na Etapa 3 necessite de ajustes. Isso deverá ocorrer enquanto os resultados obtidos na Etapa 6 não forem satisfatórios. A Etapa 8 é a etapa conclusiva. Nesse ponto, o problema deverá estar resolvido e os objetivos da pesquisa atingidos com sucesso.

\subsection{Abordagem}

Este trabalho foi elaborado utilizando a abordagem qualitativa por se adequar às características encontradas na literatura pesquisada.

Segundo Creswell (1994), para estudos qualitativos, o pesquisador precisa encontrar o mínimo de literatura, o suficiente para discutir o problema. O pesquisador usa de uma linguagem pessoal para descrever o que espera entender, descobrir ou desenvolver uma teoria. Em abordagens quantitativas, o pesquisador encontra uma sustentação firme na literatura, uma teoria avançada que deseja testar e utiliza de uma voz interpessoal na descrição das descobertas.

Para Bryman (1989), a principal característica da abordagem qualitativa, em contraste com a abordagem quantitativa, é sua perspectiva no objeto de estudo. A pesquisa quantitativa é empurrada por um conjunto de quesitos provenientes da literatura, de teorias ou de um domínio particular.

Bryman (1989) apresenta um conjunto de sete características comparativas das abordagens qualitativa e quantitativa que podem ser de grande valia para o pesquisador se orientar com relação ao caminho que deve tomar. Em síntese, as sete características são as seguintes:

- A ênfase na interpretação é muito maior nas pesquisas com abordagem qualitativa do que naquelas com abordagem quantitativa.

- Estudos quantitativos tendem a dar menor atenção ao contexto.

- A abordagem quantitativa tende a não considerar os aspectos processuais da realidade da organização.

- A abordagem quantitativa exige uma rigorosa preparação na forma de coleta de dados, o que impede a mudança da direção da pesquisa em contraste com a abordagem qualitativa em que o rumo da pesquisa pode mudar com o curso dos eventos.

- A maioria das pesquisas quantitativas utiliza uma única fonte de dados enquanto que em pesquisas qualitativas é comum o uso de múltiplas fontes.

- Pesquisas quantitativas tendem a apresentar a organização como uma combinação inerte de fatos esperando para serem revelados pelo pesquisador.

- A proximidade do pesquisador qualitativo contrasta severamente com a distância entre o pesquisador quantitativo e o objeto de estudo.

Para Godoy (2005), no estudo qualitativo, o processo de condução da pesquisa é essencialmente indutivo com o objetivo de construir conceitos, pressuposições ou teorias, ao invés de, dedutivamente, derivar hipóteses a serem testadas.

\section{Aplicação do método de Pesquisa-ação}

Este trabalho foi desenvolvido utilizando o roteiro dado por McKay e Marshall (2001) e inicia-se com a caracterização da empresa objeto de estudo. Esse roteiro foi escolhido entre outros devido a sua clareza na definição das etapas, muito importantes para o desenvolvimento deste projeto.

A seguir são descritas as etapas da pesquisa de forma sintética e esquemática. Feito isso, são descritas de forma detalhada cada uma das etapas da pesquisa. Neste ponto, é importante observar que, para melhor entendimento do problema, é necessário inicialmente a descrição de seu contexto, ou seja, a organização e o cenário de sua ocorrência. O problema propriamente dito é descrito na etapa número um.

\subsection{Caracterização da empresa objeto de estudo}

O trabalho foi desenvolvido em uma empresa agrícola do setor sucroalcooleiro produtora de cana-de-açúcar para duas usinas do mesmo grupo empresarial. Operacionalmente está organizada nos seguintes setores: Setor de Campo é onde ocorrem as atividades de plantio e colheita de cana-de-açúcar e atividades de tratos culturais e manutenção dos canaviais. É constituído por um conjunto de mais de seiscentas propriedades rurais a uma distância média ponderada de aproximadamente $25 \mathrm{~km}$. A ponderação é feita pela multiplicação da área da propriedade pela distância ao ponto de entrega e a divisão do produto pela soma total de todas as áreas. O Setor do Escritório Agrícola é onde são executadas todas as tarefas administrativas de 
planejamento agrícola e operacional, controle das atividades rurais de plantio, colheita, tratos culturais etc. O Setor de RH (Recursos Humanos) é onde são efetuados todos os controles relativos à contratação e dispensa de mão de obra rural, pagamentos dos trabalhadores, fornecimentos de informações governamentais, geração de relatórios gerenciais etc. É no Setor de Contabilidade que são processados todos os lançamentos contábeis para preparação de balancetes e apuração de resultados com objetivos financeiros, societários, fiscais e tributários. No Setor Administrativo e Financeiro, são definidas as macro estratégias da empresa, tomadas de decisões sobre captação e aplicação de recursos financeiros e feito o acompanhamento do desempenho organizacional com relação aos indicadores do mercado. O Setor de Manutenção Automotiva refere-se à oficina mecânica para manutenção preventiva e corretiva dos veículos, caminhões, tratores e equipamentos utilizados nas atividades da empresa. No Setor de Compras/Almoxarifado, são efetuadas as compras de suprimentos necessários para o desempenho das atividades agrícolas, peças para manutenção mecânica e controle da distribuição e aplicação de insumos.

Todos os setores mencionados possuem localizações distintas e, exceto o Setor de Campo, estão interconectados por rede de computadores. A Figura 3 ilustra as rotas de informação relacionadas ao controle de mão de obra.

A atividade econômica da empresa é a produção de cana-de-açúcar, que, devido ao fato de tratar-se de cultura permanente, exige o planejamento e controle de três macroatividades: plantio, colheita e tratos culturais. Cada uma destas macroatividades possui controle operacional específico e implicações contábeis distintas. No entanto, quase sempre são desempenhadas pelo mesmo quadro de funcionários.

\subsection{Etapas da pesquisa}

Para orientação do trabalho, foi elaborado um diagrama com base no modelo dado por McKay e Marshal (2001), ilustrado pela Figura 2. A Figura 4 mostra como o modelo de McKay e Marshal foi utilizado para a organização deste estudo.

O modelo ilustra de forma estática a atividade de Pesquisa-ação utilizada no trabalho, no entanto é importante salientar que esse método é naturalmente dinâmico, principalmente pelo seu caráter interativo. Outro fato que deve ser mencionado é que, embora as etapas possuam uma lógica clara de relacionamento entre elas, na prática, nem sempre o trabalho foi progressivo. Ocorreram muitas situações em que foi necessário voltar à etapa anterior para pequenos ajustes antes de prosseguir.

A seguir são descritas cada uma das etapas ilustradas na Figura 4.

\subsubsection{Etapa 1 - Identificação do problema}

A oportunidade para o desenvolvimento deste projeto de pesquisa surgiu a partir da análise conjunta, entre o pesquisador e membros da organização objeto de estudo, de um problema clássico com a contabilização de custos de mão de obra rural. A ideia inicial foi utilizar métodos pesquisados na literatura para solucionar o problema descrito a seguir.

De acordo com Marion (2002), a contabilidade de empresas rurais possui algumas particularidades. Entre elas está a alocação de custos relativos à formação e manutenção de culturas permanentes. Também foi visto que a cana-de-açúcar é uma típica cultura permanente. E que a contabilização dos custos, para este tipo de cultura, relativos a plantio, tratos culturais e colheita têm destinos muito diferentes no plano de contas.

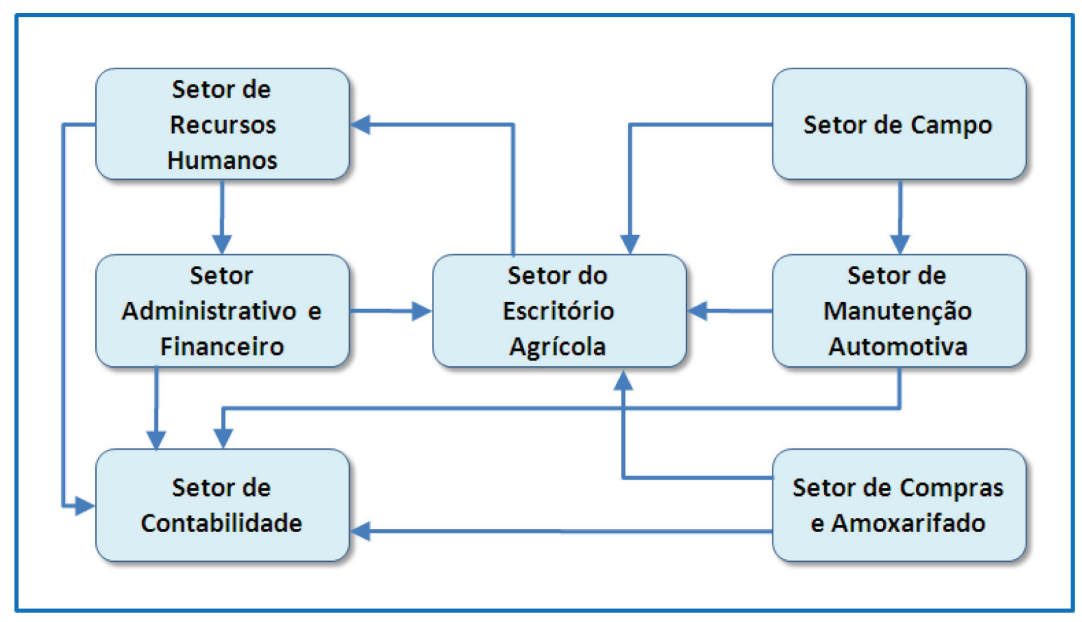

Figura 3. Rotas de informações para o controle de mão de obra. 


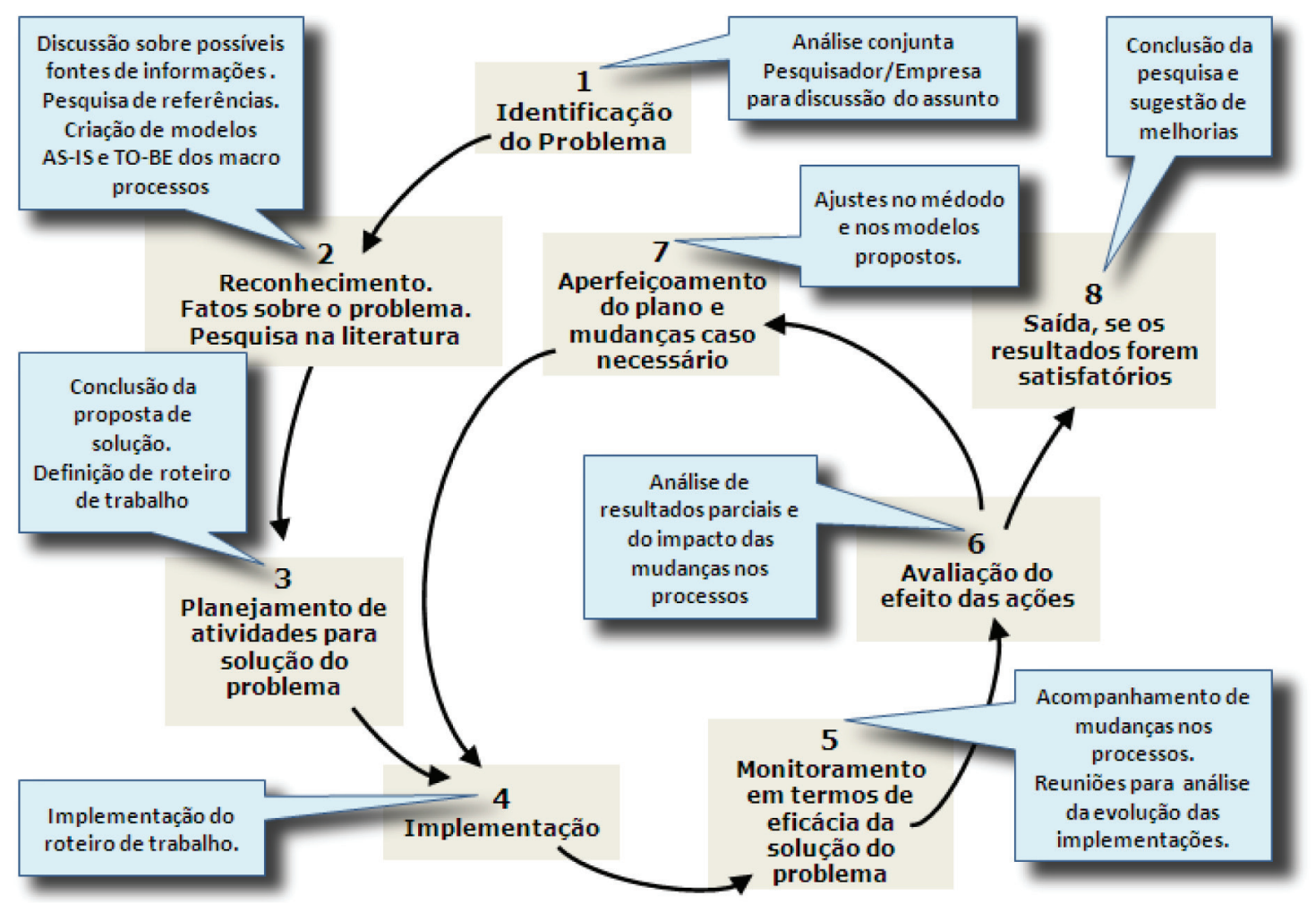

Figura 4. Roteiro de Trabalho. Fonte: Adaptado de McKay e Marshall (2001).

Um dos problemas relativos à contabilização na empresa estudada reside na alocação dos custos de mão de obra. Assim, o problema, objeto de estudo, consistiu em encontrar, a partir de um estudo sistemático do ambiente operacional e de uma revisão da literatura, uma forma de automatizar a distribuição e alocação dos custos de mão de obra e promover a sua contabilização.

\subsubsection{Etapa 2 - Reconhecimento. Fatos sobre o problema}

Inicialmente foram efetuadas visitas aos setores de Controle Agrícola, de Recursos Humanos e de Contabilidade, para o levantamento dos processos atuais relacionados ao controle de utilização e pagamento de MO (Mão de obra) e posterior contabilização.

Nessa etapa, foram vistos muitos relatórios de controles agrícolas e coletados materiais e informações sobre a utilização dos recursos de MO. Foram também construídos fluxogramas simples para facilitar o diálogo entre as partes envolvidas. A Figura 5 representa o macroprocesso da situação inicialmente encontrada ("AS-IS"). Ilustra o fluxo de informações provenientes do Setor Agrícola para a contabilização dos custos com mão de obra.

O Sistema de Controle Agrícola, cujo propósito principal é dar suporte à gestão do setor de produção de cana-de-açúcar, fornece um conjunto de relatórios gerenciais analíticos com os resultados dos apontamentos e controle de desempenho dos trabalhadores rurais. Esse Sistema gera também um conjunto de arquivos magnéticos que são utilizados pelo setor de RH (Recursos Humanos) para geração da Folha de Pagamentos.

Depois do encerramento mensal da Folha de Pagamentos, um conjunto de relatórios é disponibilizado para subsidiar a construção de planilhas com os lançamentos contábeis que são posteriormente digitados no Sistema Contábil.

O método de Custeio por Absorção é utilizado devido aos aspectos legais, porém os critérios de rateios utilizados para a montagem das planilhas Excel são arbitrários.

Um detalhe importante que pode ser observado é que os três sistemas envolvidos são de origens diferentes. O Sistema de Controle Agrícola é de desenvolvimento próprio, enquanto que os sistemas de Folha de Pagamentos e o ERP (Enterprise Resource Planning) são de fornecedores diferentes. Os verdadeiros nomes dos fornecedores chamados de "A" e "B" foram omitidos por estarem fora do propósito deste trabalho.

O principal fato sobre o problema descrito com auxílio da Figura 5 é que a montagem de planilhas e lançamentos manuais são atividades operacionais 


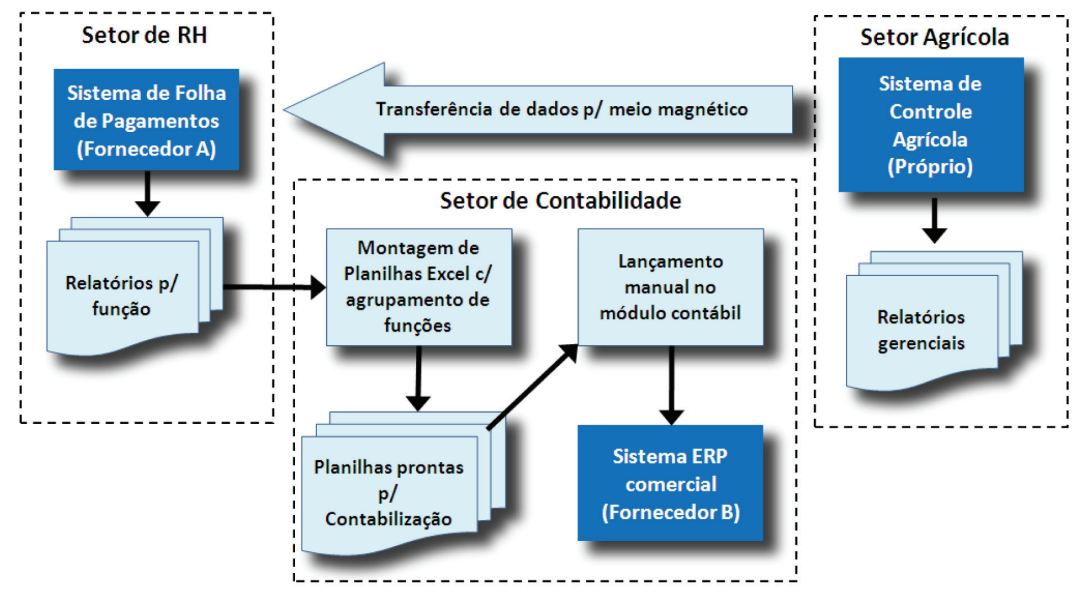

Figura 5. Situação inicial do fluxo de informação ( “AS-IS”) para contabilização dos custos mensais com MO agrícola.

altamente vulneráveis e passíveis de erros. E ainda, não utilizam de informações sobre aplicação dos recursos agrícolas, pois, nesse ponto, as informações já possuem alto nível de consolidação.

A Figura 5 também serve para visualização do problema de pesquisa, que passou a ter o seguinte enunciado: mapear os processos de controle agrícola com utilização de mão de obra; identificar direcionadores de custos viáveis para distribuição e alocação contábil dos custos de MO; dar suporte ao desenvolvimento de um sistema computacional para leitura do banco de dados do sistema do fornecedor " $A$ " e efetuar automaticamente os lançamentos contábeis no banco de dados do fornecedor " $B$ ", com a utilização dos direcionadores provenientes do Sistema de Controle Agrícola.

Assim, foi possível a elaboração de um diagrama do macro processo desejado para o futuro ( "TO-BE") para a apropriação automática dos custos mensais com MO. A Figura 6 ilustra a proposta para a solução do problema.

O ponto-chave dessa solução está na identificação dos direcionadores de custos adequados à apropriação dos custos de MO com a maior fidelidade possível à utilização dos recursos agrícolas. Obviamente, para isso, o conhecimento dos processos agrícolas e implementação de possíveis mudanças nos controles e utilização de recursos seria de fundamental importância.

Nesta etapa, foi efetuada uma pesquisa na literatura com o objetivo de encontrar soluções de problemas análogos ao objeto deste estudo que pudessem ser utilizadas ou adaptadas para este trabalho. Embora não tenha sido encontrada nenhuma solução que pudesse ser aplicada diretamente, foram identificadas várias referências que serviram para nortear o desenvolvimento deste projeto (BAYKASOGLU; KAPLANOGLU, 2008; MARION, 2002; MARTINS, 2006; McKAY; MARSHALL, 2001; NAKAGAWA,
2001; PADOVEZE, 2003; THIOLLENT, 1997, 2005; TORNBERG; JÄMSEN; PARANKO, 2002).

\subsubsection{Etapa 3 - Planejamento de atividades}

Com base na revisão da literatura sobre custos de produção, optou-se pela manutenção do modelo de custeio por absorção, porém utilizando os princípios de distribuição de custos com a utilização de direcionadores de custos, utilizados pelo método $\mathrm{ABC}$, em substituição aos critérios arbitrários de rateio.

Isso porque, conforme afirma Padoveze (2003), o método de Custeio por Absorção atende às exigências fiscais e societárias. Enquanto Martins (2006) afirma que, para a alocação dos custos indiretos, é necessária uma análise de seus componentes para definir os melhores critérios de rateio que relacionam os custos aos produtos. Dessa forma, optou-se pela utilização do método de distribuição dos custos com base no consumo dos recursos pelas atividades em substituição aos critérios arbitrários.

Para a distribuição e alocação de custos de mão de obra, foi adotado o modelo apresentado pela Figura 7.

Um ponto importante que se observa na Figura 7, com relação ao modelo original de Cogan (1999), é que no lugar de "Centros de Atividades" foram colocadas as atividades individuais, e seus custos são alocados a centros de custos e não diretamente aos produtos. Isso se deve ao fato de se tratar de empresa agrícola com cultura permanente, que possui tratamentos especiais, tal como foi descrito por Marion (2002), e também porque este trabalho teve como foco somente os custos de mão de obra e não o sistema de custeio como um todo.

Para a implementação do modelo descrito pela Figura 7, elaborou-se um roteiro de trabalho semelhante à abordagem utilizada por Baykasoglu e Kaplanoglu (2008), ilustrado pela Figura 8. 


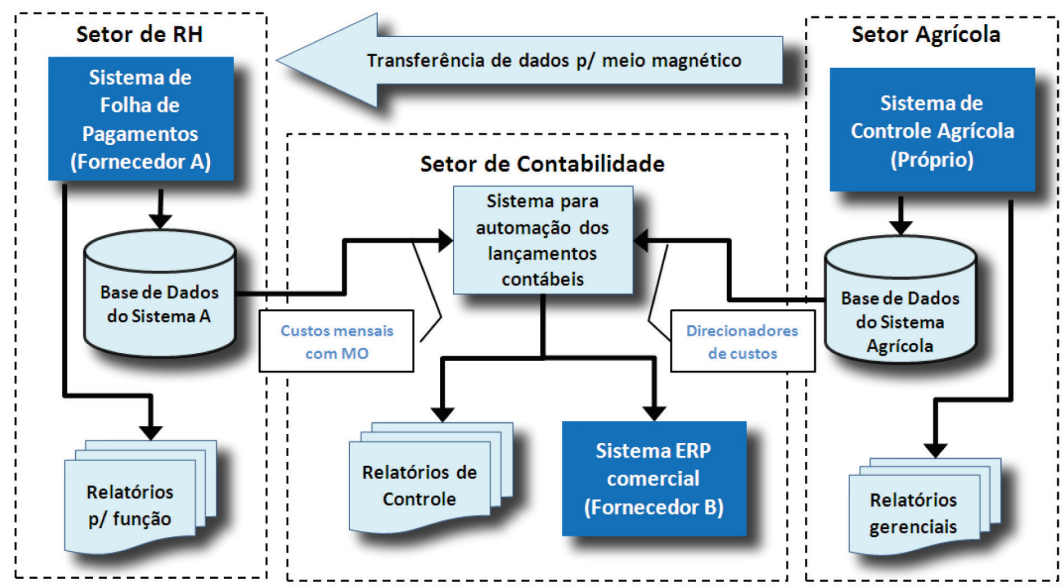

Figura 6. Processo desejado para apropriação automática dos custos mensais com MO agrícola ("TO-BE”).

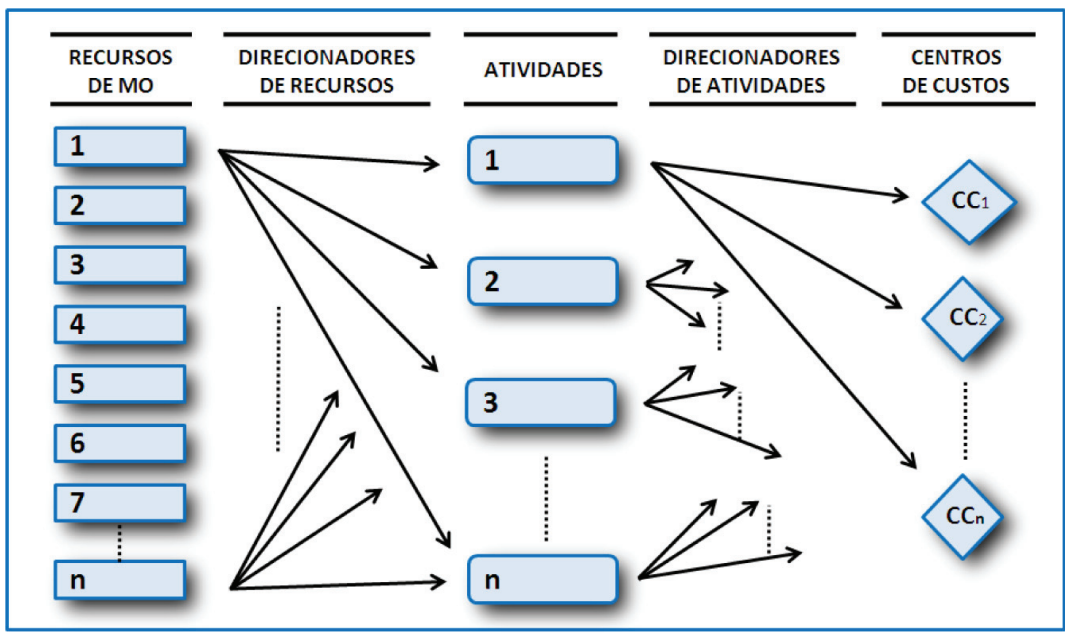

Figura 7. Distribuição dos custos de mão de obra. Fonte: Adaptado de Cogan (1999).

O Roteiro ilustrado na Figura 8 é composto pelas seguintes macrotarefas:

- Determinação dos processos, atividades e recursos de MO: Consiste em visitar os locais de utilização de recursos de mão de obra e promover entrevistas com os encarregados e administradores locais para captura e registro de conhecimento sobre os controles existentes.

- Coleta de dados das atividades e dos recursos de MO: Consiste na obtenção de planilhas manuais e eletrônicas, relatórios de controle utilizados no controle da aplicação de mão de obra nas atividades envolvidas no processo produtivo e registro de observações locais.

- Modelagem e mapeamento dos processos com uso de MO: Este é o ponto crucial do roteiro, pois, como afirma Savi, Amaral e Rozenfeld (2002), os modelos de processos de negócios permitem uma visão integrada do conhecimento sobre os processos. E ainda, essa visão serve de referencial comum, padronizando e facilitando a interação entre os diferentes profissionais envolvidos no processo de negócio. Para execução dessa macrotarefa foi necessário um procedimento inicial para a definição das técnicas e ferramentas utilizadas no projeto.

- Seleção e validação dos direcionadores de custos: A seleção consiste na análise conjunta (pesquisador/organização) dos modelos de processos de negócios obtidos no passo anterior para, com uso de um critério definido, a partir da revisão da literatura, selecionar direcionadores de custos adequados e viáveis para o projeto. A validação consiste na verificação da fidelidade dos modelos dos processos analisados e da adequação dos direcionadores encontrados com o critério 


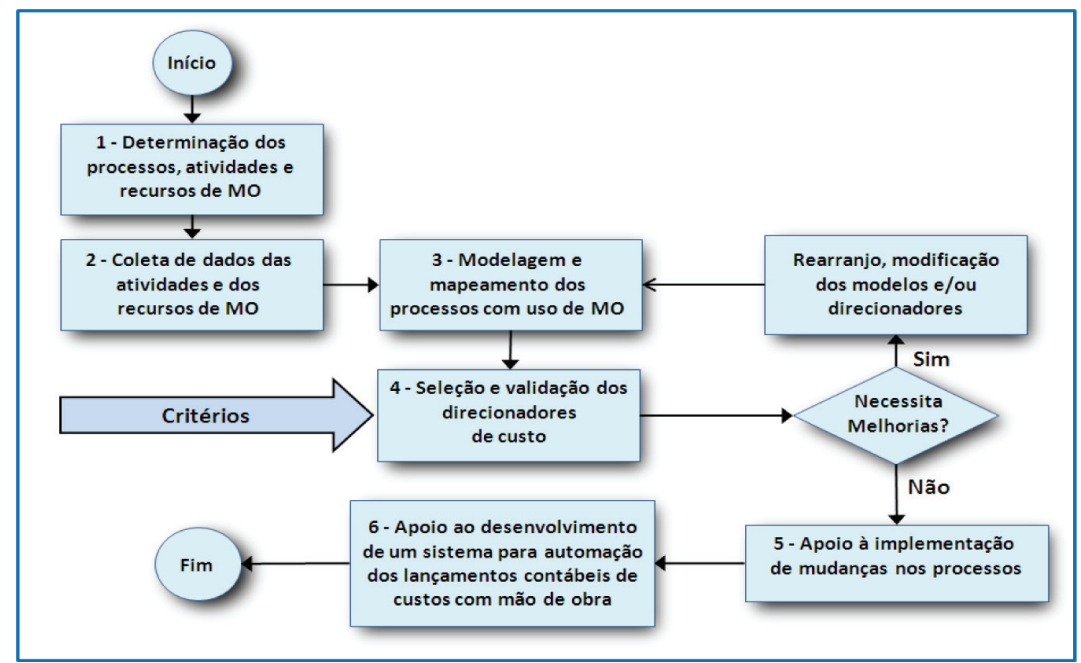

Figura 8. Roteiro utilizado na etapa de implementação.

de seleção. Serve também, para a discussão de sugestões de melhorias nos processos e proposta de novos direcionadores obtidos a partir de mudanças nos processos.

O resultado desse passo leva à decisão sobre uma das seguintes situações:

Caso exista alguma restrição ou necessidade de melhorias na definição dos direcionadores ou modelos de processos será necessário o retorno ao passo $\mathrm{n}^{\circ} 3$.

Ou então, após a certificação dos modelos de processos, e com os direcionadores de custos definidos, deverá ser elaborada documentação necessária para dar suporte à implementação de melhorias e adequações aos processos para obtenção dos direcionadores escolhidos.

- Apoio à implementação de mudanças nos processos: Esse passo consiste em apoiar as implementações de mudanças nos processos para adequação aos requisitos necessários à obtenção dos direcionadores de custos.

- Apoio ao desenvolvimento do sistema para automação dos lançamentos de custos com MO: Consiste em fornecer conhecimento e material aos analistas e programadores para o desenvolvimento de um sistema de automação dos lançamentos de custos de MO.

Depois da elaboração do roteiro básico iniciaram-se os procedimentos para sua implementação.

\subsubsection{Etapa 4 - Implementação}

Essa etapa consistiu na implementação do roteiro definido na etapa anterior, entretanto, relembrando Nakagawa (2001), para a implementação de uma metodologia $\mathrm{ABC}$, é muito importante o suporte e participação da alta administração. Por isso, antes de iniciar os passos descritos pelo roteiro da Figura 8, foi feita uma reunião envolvendo diretores, contadores, administradores de $\mathrm{RH}$, principais encarregados e operadores do Sistema de Controle Agrícola para exposição e conscientização de todos os envolvidos com relação aos seguintes pontos:

- Nivelamento do conhecimento sobre os processos de utilização de MO;

- Apresentação dos motivos do conhecimento da alocação dos recursos de acordo com as atividades;

- Apresentação da Figura 8 com justificativas sobre sua importância para a apropriação mais adequada dos custos com MO;

- Busca do comprometimento de todos com a implementação do projeto.

Nessa etapa, a modelagem e mapeamento de processos representaram um papel muito importante com a criação de uma visão comum entre os participantes. Como afirmam Tornberg, Jämsen e Paranko (2002), o objetivo da MPN (Modelagem de Processos de Negócios) é ajudar as companhias a melhorar o entendimento sobre os processos. E ainda, a modelagem qualitativa de um processo tem como foco a sua visualização para se conseguir uma concordância sobre sua estrutura. No entanto, consideram que a MPN não é uma condição necessária para a implementação do método de custeio $\mathrm{ABC}$, porém, caso seja usada simultaneamente, importantes informações sobre os processos podem ser conseguidas mais facilmente.

Rozenfeld (1996) afirma que, a ABM (Activity Based Management) preconiza que se deve analisar as atividades para otimizá-las, antes de serem custeadas pelos seus direcionadores e, portanto, o conhecimento do BP (Business Process) é essencial. 


\subsubsection{Etapa 5 - Monitoramento}

Esta etapa da pesquisa consistiu na participação ativa do pesquisador na implantação das medidas para mudanças dos processos, com formulação de sugestões e auxílio na validação dos resultados das tarefas. O mesmo ocorreu no desenvolvimento do Sistema para automação dos lançamentos contábeis de apropriação dos custos de MO.

O ponto importante desta etapa foi a verificação da evolução do projeto para garantir que o roteiro elaborado estava sendo adequado para se atingir os objetivos iniciais.

\subsubsection{Etapa 6 - Avaliação do efeito das ações}

À medida que se implementava mudanças nos processos, eram feitas reuniões para avaliação dos resultados obtidos e discussão sobre as dificuldades encontradas. Quando ocorria algum problema inesperado, sua solução era implementada com a colaboração dos participantes, o que justifica a importância das reuniões de avaliação.

\subsubsection{Etapa 7 - Aperfeiçoamento do Plano de Ações}

Essa etapa proposta no projeto de pesquisa-ação não ocorreu de forma explícita e isolada, isto porque as ocorrências de necessidades de melhorias do plano de trabalho, quando detectadas eram resolvidas imediatamente. Isto foi possível porque o pesquisador, durante o desenvolvimento do projeto, permanecia na empresa objeto de estudo dois ou três dias por semana.

\subsubsection{Etapa 8 - Conclusão dos ciclos da Pesquisa-ação}

O projeto foi considerado concluído quando as mudanças nos processos foram implementadas e a contabilização dos custos de MO já estava automatizada. No entanto, ainda havia a necessidade de muitas conferências devido a inconsistências com os lançamentos de atividades no Setor de Campo. Para resolver esses problemas novas melhorias deviriam ser estudadas.

\section{Conclusões}

É interessante relatar que a ideia deste trabalho surgiu em uma pré-revisão de literatura, quando o pesquisador buscava uma solução para melhoria do processo de apropriação dos custos MO na empresa objeto de estudo. Foi assim que o pesquisador identificou essa oportunidade de pesquisa, principalmente a partir das seguintes considerações:
- A empresa não possuía os processos documentados e a literatura revisada recomendava fortemente o uso de MPN para o conhecimento de processos e introdução de melhorias.

- Seria necessária a aquisição de conhecimento sobre sistemas de custeio para identificar o método mais adequado para a solução desejada.

- Uma boa revisão de literatura poderia revelar soluções já implementadas em problemas semelhantes que poderiam ser adotadas e validadas.

Outro ponto a ser considerado é que a própria natureza do problema exigia uma abordagem participativa, pesquisador/organização, pois a solução era de interesse de ambos e seria necessário um estudo sistêmico e a obtenção de conhecimento implícito nos processos. Nesse ponto, podemos citar Thiollent (2005, p. 93):

\begin{abstract}
Nos últimos anos, a pesquisa-ação tem sido pensada como instrumento adaptado ao estudo, em situação real, das mudanças organizacionais que acompanham a introdução de novas tecnologias, principalmente as baseadas na informática.
\end{abstract}

A abordagem acadêmica com o uso do método de Pesquisa-ação mostrou-se totalmente adequada à solução do problema estudado. O caráter interativo do método, com o envolvimento do pesquisador com as ações implementadas, sempre amparadas com a revisão da literatura, teve grande importância para a convergência para os resultados esperados.

\section{Referências}

BAYKASOGLU, A.; KAPLANOGLU, V. Application of Ativity-based Costing to a Land Transportation Company: A Case Study. International Journal of Production Economics, v. 116, n. 2, p. 308-324, 2008. http://dx.doi.org/10.1016/j.ijpe.2008.08.049

BRYMAN, A. Research Methods and Organization Studies. London: Unwin Hymank, 1989. p. 135-167. http://dx.doi.org/10.4324/9780203359648_chapter_5

CAZZOLATO, N. K. Resenha Bibliográfica: Pesquisa-ação nas organizações. Organizações em contexto, v. 4, n. 7, jun. 2008.

COGAN, S. Custos e preços: formação e análise. São Paulo: Pioneira, 1999.

COUGHLAN, P.; COGHLAN, D. Action Research For Operations Management. International Journal of Operations \& Production Management, v. 22, n. 2, p. 220-240, 2002. http://dx.doi. org/10.1108/01443570210417515

CRESWELL, J. W. Research Design. Quantitative and Qualitative Approaches. London: Sage, 1994. p. 173-193.

CUNHA, P. R.; FIGUEIREDO, A. D. Action-research and critical rationalism: a virtuous marriage. In: EUROPEAN CONFERENCE ON INFORMATION 
SYSTEMS, 10., 2002, Gdańsk, Poland. Proceedings... ECIS, 2002. p. 19-27.

DICK, B. A beginner's guide to action research. 2000. Disponível em: <http://www.scu.edu.au/schools/gcm/ ar/arp/guide.html>. Acesso em: 25 jun. 2010.

GODOY, A. S. Refletindo Sobre Critérios de Qualidade da Pesquisa Qualitativa. Revista Eletrônica de Gestão Organizacional, v. 3, n. 2, maio/ago. 2005.

HOLANDA, V. B.; RICCIO, E. L. A utilização da PesquisaAção para perceber e implementar sistemas de informações empresariais. 2010. Disponível em: $<$ http://www.ccsa.ufrn.br/depad/simulacaoempresarial/ downloads/textos/Utiliza\%E7\%E3o\%20de\%20pesquisaa\%E7\%E3o.pdf>. Acesso em: 25 jun. 2010.

MARION, J. C. Contabilidade rural: contabilidade agrícola, contabilidade da pecuária, imposto de renda pessoa jurídica. 7. ed. São Paulo: Atlas, 2002.

MARTINS, E. Contabilidade de Custos. 9. ed. São Paulo: Atlas, 2006.

McKAY, J.; MARSHALL, P. The Dual Imperatives of Action Research. Information Technology \& People, v. 14, n. 1, p. 46-59, 2001. http://dx.doi. org/10.1108/09593840110384771

NAKAGAWA, M. ABC: custeio baseado em atividades. 2. ed. São Paulo: Atlas, 2001.
PADOVEZE, C. L. Curso básico gerencial de custos. São Paulo: Thomnson, 2003.

ROZENFELD, H. Reflexões sobre a Manufatura Integrada por Computador (CIM). São Carlos: EESC-USP, 1996. Disponível em: <http://www.numa.org.br/grupos_numa/ grupo_ei/Projetos\%20EI/Txtei0123.pdf>. Acesso em: 27 jun. 2006.

SAVI, A. F.; AMARAL, D. C.; ROZENFELD, H. Aplicação de modelos de processos de negócio em soluções para gerenciamento de conhecimento no processo de desenvolvimento de produto. In: KMBRASIL - CONGRESSO ANUAL DA ASSOCIAÇÃO BRASILEIRA DE GESTÃO DO CONHECIMENTO, 2002, São Paulo. Anais... KMBrasil, 2002.

THIOLLENT, M. Pesquisa-Ação nas Organizações. São Paulo: Atlas, 1997.

THIOLLENT, M. Metodologia da Pesquisa-ação. São Paulo: Cortez Editora, 2005.

TORNBERG, K.; JÄMSEN, M.; PARANKO, J. Activity-based Costing and Process Modeling for Cost-conscious Product Design: A Case Study in a Manufacturing Company. International Journal Production Economics, n. 79, p. 75-82, 2002. http:// dx.doi.org/10.1016/S0925-5273(00)00179-1 